\title{
MITIGATION OF FIRE-INDUCED PROGRESSIVE COLLAPSE OF STEEL FRAMED STRUCTURES USING BRACING SYSTEMS
}

\author{
Jian Jiang ${ }^{1}$ and Guo-qiang $\mathrm{Li}^{2}$, * \\ ${ }^{1}$ State Key Laboratory for Geomechanics \& Deep Underground Engineering, China University of Mining and Technology, Xuzhou 221116, China \\ ${ }^{2}$ State Key Laboratory for Disaster Reduction in Civil Engineering, Tongji University, Shanghai 200092, China \\ *(Corresponding author: E-mail: gqli@tongji.edu.cn)
}

\section{A B S T RA C T}

This paper investigates disproportionate collapse resistance of braced steel frames exposed to fire. The influence of type, number and location of bracing systems on the global collapse is studied. The results show that using braces can enhance the fire-induced collapse resistance by 1 hour. For a single-compartment fire, the collapse can be prevented by using either horizontal or vertical braces. The presence of vertical braces at interior bays is essential to prevent collapse. It is neces sary to use a combined horizontal and vertical bracing to prevent collapse for interior multi-compartment fires. For multi-compartment fires at corner, fire protections are required for the perimeter columns to prevent global collapse. Slabs have beneficial influence on the collapse resistance which can be resisted by a tensile ring around the peri meter of the heated slab, and also by tensile yield lines extended to the frame edge. It is suggested to ensure the fire partition at corner regi on to avoid fire spread to adjacent compartments since spreading of corner fires are more dangerous than that of interior fires.

\section{AR T I CLE H IS T O RY}

$\begin{array}{ll}\text { Received: } & 27 \text { July } 2018 \\ \text { Revised: } & 14 \text { November } 2018 \\ \text { Accepted: } & 18 \text { November } 2018\end{array}$

\section{K E Y W O R D S}

Disproportionate collapse

Steel framed structure

Horizontal bracing;

Vertical bracing;

Compartment fire;

Combination of bracing

\section{Copyright $\odot 2019$ by The Hong Kong Institute of Steel Construction. All rights reserved.}

\section{Introduction}

Since the Broadgate Phase 8 fire in London and the subsequent Cardington fire tests [1] in the 1990s, researchers have begun to investigate and understand the behavior of whole steel-framed structures in fire. It was confirmed that steel members in real multi-story buildings had significantly greater fire resistance than isolated members in standard fire tests. Especially since the collapse of Word Trade Tower (WTC) under the terrorist attack on September 11, 2001, there have been growing interests in understanding disproportionate or progressive collapse mechanism of structures under accidental loads [2-6]. The term "disproportionate collapse" is defined as "the spread of an initial local failure from element to element, eventually resulting in the collapse of an entire structure or a disproportionately large part of it" [7]. It implies that large displacements, even failure, of individual structural members are acceptable given the prevention of global structural collapse.

As specified in various design codes [8,9], a common approach, called alternate path method, is applied by instantaneously removing the potentially damaged column (simulating the local damage), and assessing the progressive collapse resistance of the remains to ensure there are alternative load transferring paths to bridge over the missing member. However, this methodology is more applicable to blast or impact rather than fire effect, although it is typically considered to be "threat independent". Firstly, the duration of fire (in hour) is much longer than that of blast (in millisecond), and thus the behavior of structures exposed to fire is a quasi-static process until the failure of heated members [10]. Secondly, the time when a structure collapses (i.e. fire resistance) is a key factor apart from whether it collapses. This fire resistance against structural collapse depends on the failure process of heated members which should be explicitly simulated in numerical models. In addition, only one column is removed each time in the alternate path method compared to several members simultaneously heated in the case of fire. Therefore, the local failure of all heated elements should be included in the structural analysis of buildings exposed to fire to ensure an accurate prediction of both collapse time and collapse mode.

A review of fire-induced collapse mechanism of steel structures refers to the reference [11]. Usmani et al. [12] investigated the stability of WTC tower exposed to fire alone, based on a two-dimensional (2D) model. The results showed that the tower collapsed due to the loss of lateral support for columns. The details of this collapse mechanism were further studied [13-15]. It was found that the main reason for the collapse was the low membrane capacity in compression of the truss floor. Two collapse mechanisms, namely weak floor failure mechanism and strong floor failure mechanism, were proposed. Quiel and Garlock [16] compared the numerical results of 2D and 3D models of steel frames in fire. It was concluded that a 2D model was sufficient to provide a reasonable prediction if the slab was considered in the thermal analysis which can be neglected in the structural analysis. However, their studies did not consider complete collapse due to numerical convergence issues where the tensile membrane action of floors would have a significant influence. Sun et al. [17] found that lower load ratios and larger beam sections could result in a global collapse. Jiang et al. $[18,19]$ studied the effect of fire scenarios on the collapse mechanism of 2D steel frames under fire. Four collapses modes were proposed including the global and local downward and lateral collapse. The effect of catenary action of beams and load ratio of columns was investigated [20], where only one column was assumed exposed to fire.

Most previous studies focus on 2D planar frames. Although capable of capturing some key issues of the fire-induced collapse mechanisms of structures, they fail to fully consider the load redistribution path in a realistic structure [21], and especially the effect of floors through composite action to steel beams [22] and tensile membrane action [23, 24]. More recently, there are growing interests in three-dimensional (3D) modeling of steel framed structures. Pyl et al. [25] investigated the fire safety of a single-story portal frame where limited load transfer paths were available. Kilic and Selamet [26] investigated the fire-induced collapse modes of a 49-storey steel frame. It indicated that the location of fire on a single floor did not significantly change the collapse mechanism. This conclusion was questionable because it assumed that all the columns on one floor were heated which was an extreme situation. Agarwal and Varma [27] studied the fire-induced progressive collapse of a 10 -storey steel building. It was found that the columns played a key role in the overall stability of the building. The collapse mechanism of a 3D 8-storey steel frame with concrete slabs was studied by Jiang and Li [28,29]. It was found that the fire protection of steel members had a significant influence on the resistance of structures against fire-induced collapse. A protected frame did not collapse immediately after the local failure but experienced a relatively long withstanding period of at least $60 \mathrm{~min}$ [29]. A comparison between 2D and 3D models [29] showed that the $2 \mathrm{D}$ model produced conservative results by underestimating the collapse resistance, and it cannot capture the load redistribution in a 3D model where more loads were distributed along the short span than those along the long span. Therefore, the collapse mechanism of steel framed structures exposed to fire has been comprehensively investigated through 2D and 3D models. The collapse will be triggered by the buckling of the heated columns followed by lateral drift of adjacent cool columns, which is driven by the catenary action of the heated beams or tensile membrane action of the heated floors. Therefore, it is necessary to further investigate measures to improve the disproportionate collapse resistance of structures given these identified collapse mechanisms, which is the objective of this paper.

The FEMA report [30] on the collapse of WTC towers proposed a call to determine "whether there are feasible design and construction features that would permit such buildings to arrest or limit a collapse, once it began". Preventing the spread of local failure is the key to ensure the resistance to disproportionate collapse. Increasing structural redundancy is an effective way to enhance the robustness of structures against collapse. Some attempts have been made to answer the FEMA call by using bracing systems to enhance redundancy of structures at ambient temperatures. The results showed that the 
braced frames had good collapse resistance under various column removal scenarios [31, 32]. The collapse may be triggered by the buckling of compression braces followed by the buckling of columns [32]. The frame with two braced bays had more robustness for mitigating collapse than that with three braced bays [33]. The effectiveness of using hat braces and vertical braces were verified [34,35]. Main and Liu [36] compared the robustness of 3D moment frames and braced frames against column loss, and they recommended to make all perimeter columns as part of a braced frame. Most previous studies on disproportionate collapse of braced frames at ambient temperatures focus on 2D models, and the effect of bracing systems on the stability of 3D frames needs further investigation.

In the case of fire, the application of bracing systems to improve disproportionate collapse resistance of steel frames is not well established in the literature. Sun et al. [37] and Jiang et al. [38] found that using hat trusses on the top of the frame exposed to fire facilitated the load redistribution to columns, but failed to resist the lateral drift of columns which may lead to a global downward collapse. A vertical bracing system can act as a barrier to prevent the spread of local failure to the rest of structures. It was recommended to use a combined bracing system in practical design. Nevertheless, all these studies are based on 2D models, and their validity and generalization in practice is questionable when it comes to 3D structures. The main objective of this paper is to investigate the influence of bracing systems on mitigating disproportionate collapse of 3D steel framed structures exposed to fire.

This paper presented numerical analysis of fire-induced disproportionate collapse of three-dimensional steel framed structures. An 8-storey steel frame with reinforced concrete slabs was designed and analyzed for various fire scenarios and layouts of bracing systems. These include single-compartment fires and multi-compartment fires at interior and at corner of the frame, respectively. The effect of horizontal and vertical bracing systems on the collapse resistance of the frame under these fire scenarios was investigated. Recommendations for the selection of bracing systems were proposed to provide a guide for fire-resistant design of steel frames against disproportionate collapse.

\section{Modeling of prototype building}

\subsection{Design of prototype frame}

An 8-storey moment resisting steel framed building was modeled as a prototype structure in finite element software LS-DYNA, as shown in Figure 1. Details of the frame configuration are presented in Jiang et al. [28] and are briefly summarized herein. The structural layout and member dimensions were based on the building in Cardington fire tests [1]. The frame had five bays of $6 \mathrm{~m}$, five spans of $9 \mathrm{~m}$ and eight storey of $4 \mathrm{~m}$. All connections were assumed rigid in this study, which is the common practice for steel frame buildings in seismic zones in China. All the primary beams and columns were taken as UB $356 \times 171 \times 51$ and UC $305 \times 305 \times 198$, respectively. Reinforced concrete slabs were simulated in the model with a thickness of $120 \mathrm{~mm}$ and reinforcing bars in a diameter of $12 \mathrm{~mm}$ and spacing of $200 \mathrm{~mm}$. A uniformly distributed load of $6 \mathrm{kN} / \mathrm{m}^{2}$ was imposed on the slabs.

The steel columns and beams were simulated by three-dimensional Hughes Liu beam elements, where the local buckling of beams or columns cannot be simulated by this element (only global buckling was considered). The slabs were modeled by layered shell elements, in which a distinct structural material, thermal material, and thickness can be specified for each layer (*PART_COMPOSITE). This allows distinct layers to be specified for the reinforcement, except for concrete through the thickness of the slab. An explicit dynamic analysis was carried out which can better capture the buckling of heated columns and post-buckling behavior of the remains than the implicit analysis. The explicit analysis overcomes convergence problems of implicit analyses by avoiding the calculation of the inverse of structural stiffness matrices. However, the avoidance of iterations in explicit analysis is at the expense of requiring extremely small time steps to ensure a stable and accurate prediction. To save the computing cost of explicit analysis, the hour's real fire time has to be scaled down to seconds' computing time without causing oscillation. Sensitivity analyses were conducted to determine the appropriate time scale [28], and the results showed that it was possible to run an 8-second explicit analysis instead of 1-hour heating in a standard fire. A default automatic adjustment of time steps in LS-DYNA, in an order of $10^{-6} \sim 10^{-5} \mathrm{~s}$, was adopted for the explicit analysis in this study. This allows quasi-static responses before the buckling of the heated column and dynamic post-buckling responses. The numerical model has been validated against test results of a axially load column at ambient temperatures, a restrained steel column at elevated temperatures, simply supported reinforced concrete slab exposed to fire [28].

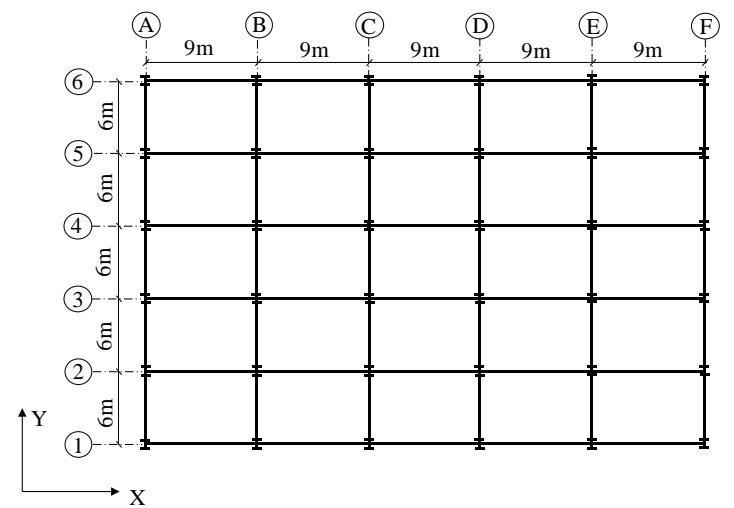

(a)

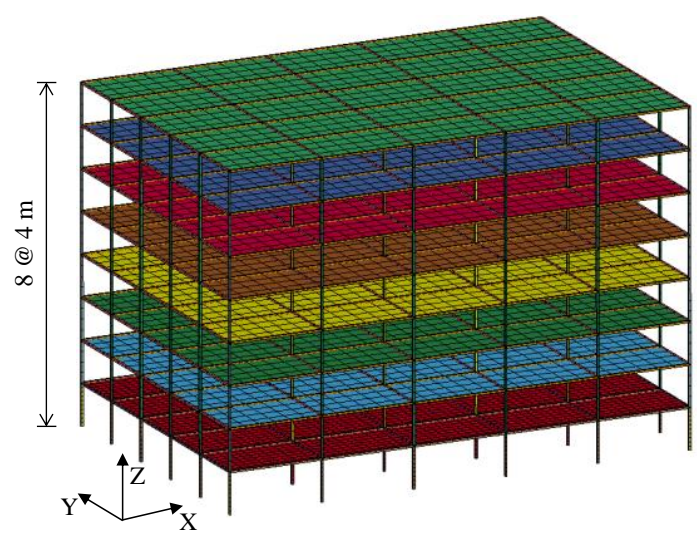

(b)

Fig. 1 Model of a 3D multi-storey moment resisting frame: (a) plan view; (b) finite element model

\subsection{Design of fire scenarios}

The ISO 834 standard fire was used, and it was assumed that the slabs, columns and beams in the fire compartment were uniformly heated up to 4 hours. Figure 2 shows the layouts of fire scenarios taken in this study. Single-compartment and multi-compartment fires were considered where all fires were assumed on the ground floor. The fire occurrence on the ground floor is considered to be the severest fire scenario compared to upper floors since the ground-floor columns have the largest load ratio compared to upper columns. A single-compartment fire at center of the ground floor (1-Fire-Center) and a fire at corner (1-Fire-Corner) were used (Figure 2a). The fire spread in the horizontal plane rather than vertical direction was accounted for in this study. This is because that the vertical fire spread has little effect on the collapse mode of structures, while the horizontal fire spread is prone to cause a global downward collapse of structures [18]. The horizontal multi-compartment fires include three interior compartments along the short span (3-Fire-Short), three interior compartments along the long span (3-Fire-Long), and four compartments at corner (4-Fire-Corner). It was assumed that all the fire compartments had the same temperature-time curve.

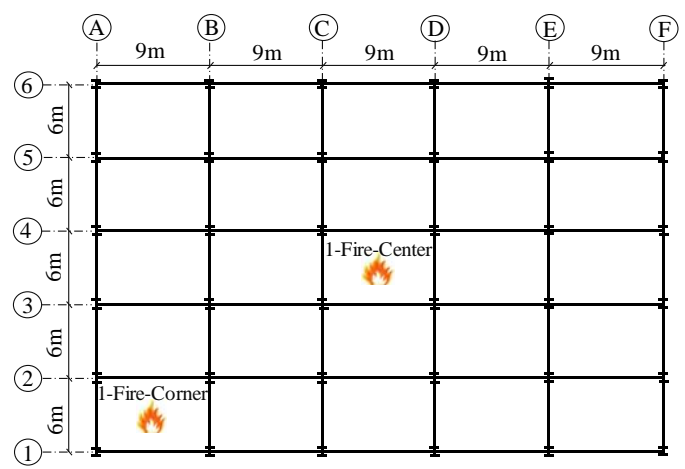




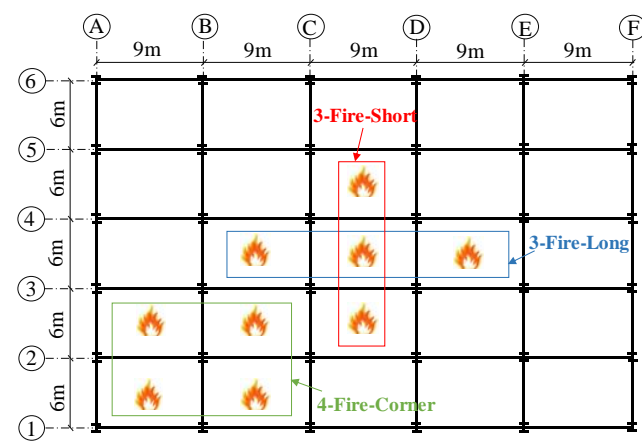

(b)

Fig. 2 Layout of fire scenarios: (a) single-compartment fire; (b) multi-compartment fire

\subsection{Temperature and material properties}

Four-side and three-side fire exposures were assumed for the heated columns and beams, respectively. The temperature of the unprotected beams and columns exposed to fire was calculated according to EN 1993-1-2 [39], as shown in Figure 3a. The figure also shows the temperature time history of protected columns with a fire rating of 3 hours. This represents a high level of fire protection which was used in Section 5 as a mean to enhance the collapse resistance. A linear temperature history was assumed for the protected columns [40], varying from an initial value of $20{ }^{\circ} \mathrm{C}$ to a predefined critical temperature of $550{ }^{\circ} \mathrm{C}$. The temperature distribution through the depth of the heated slab was taken from EN 1994-1-2 [41], as shown in Figure 3b. It was assumed that the temperature of reinforcement was taken as that of concrete at the same height.

The Young's modulus and yield strength of steel beams and columns were $200 \mathrm{GPa}$ and $355 \mathrm{MPa}$, respectively. The compressive strength of concrete was $35 \mathrm{MPa}$ and the yield strength of reinforcement was $500 \mathrm{MPa}$. The MAT_202 (MAT_Steel_EC3) was used for steel beams and columns at ambient and elevated temperatures. The temperature-dependent material properties of steel refer to EN 1993-1-2 [39]. The material MAT_172 (MAT_CONCRETE_EC2) was used to model the reinforced concrete slab at ambient and elevated temperatures. The temperature-dependent properties of concrete and reinforcement are as specified in EN 1993-1-2 [42], as shown in Figure $3 \mathrm{~b}$. It was assumed that the temperature of reinforcement was taken as that of concrete at the same location.

\subsection{Design of bracing systems}

Bracing systems have been widely used in seismic design of structures to improve lateral load resistance. In this study, inverted V-bracing systems, commonly applied in concentrically braced frames (CBF), were used in this study. A square hollow structural section (HSS) was used, and its dimension was determined for special concentrically braced frames (SCBF) according to AISC 341 [43]. SCBFs are a special class of CBFs that are proportioned and detailed to maximize inelastic drift capacity. The slenderness ratio and width-to-thickness ratio of braces for SCBF should satisfy the following requirements:

$l / r \leq 4 \sqrt{E / F y}$

$b / t \leq 0.64 \sqrt{E / F y}$

In this case, the effective lengths $(l)$ of braces along the long and short span are $6 \mathrm{~m}$ and $5 \mathrm{~m}$, respectively. Considering $E=200 \mathrm{GPa}$ and $F_{\mathrm{y}}=355 \mathrm{MPa}$, it can be calculated that $4 \sqrt{E / F y}=94.9$ and $0.64 \sqrt{E / F y}=15.2$. The results of $6-\mathrm{m}$ and $5-\mathrm{m}$ braces used for various storey are shown in Tables 1 . All the braces satisfied the requirements in Eq. (1), except the 6-m brace on the top storey of the frame (with a difference of $9 \%$ ). This discrepancy is acceptable since that the limit on the $l / r$ is very hard to satisfy when the braces also need to satisfy the $b / t$ requirement [44].

Two types of bracing systems were adopted in this study: vertical bracing system placed along the entire height of the building and horizontal bracing system placed on individual floors (i.e. hat brace and belt brace). The hat brace is arranged on the top storey of the frame, while the belt brace on the interior storey. The influence of the type, number and location of bracing systems on the collapse resistance of frames was investigated in the following sections. The collapse behavior of unbraced frames exposed to fire was first presented, followed by braced frames under single-compartment and multi-compartment fires. All the steel members were unprotected, except where specifically noted.

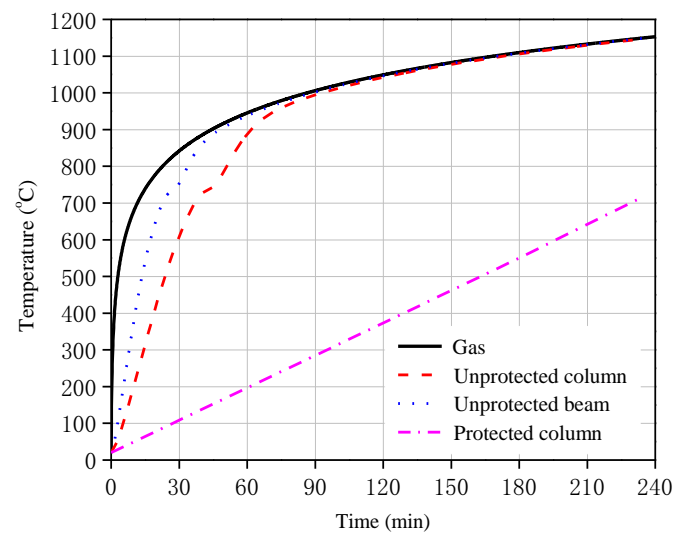

(a)

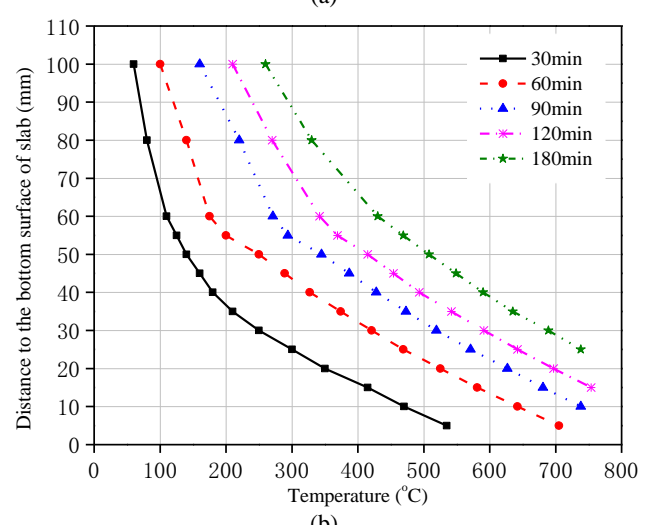

(b)

Fig. 3 Temperature-time history of heated structural members: (a) steel beams and columns; (b) reinforced concrete slabs

Table 1

Design of braces for SCBF

\begin{tabular}{|c|c|c|c|c|c|c|}
\hline \multirow{2}{*}{ Storey level } & \multicolumn{3}{|c|}{ 6-m braces along the long span for SCBF } & \multicolumn{3}{|c|}{$5-\mathrm{m}$ braces along the short span for SCBF } \\
\hline & cross section $(\mathrm{mm})$ & $l / r$ & $b / t$ & cross section $(\mathrm{mm})$ & $l / r$ & $b / t$ \\
\hline 8 & HSS $152 \times 152 \times 10$ & 103.6 & 14.2 & HSS $140 \times 140 \times 10$ & 94.6 & 12.8 \\
\hline 7 & HSS $152 \times 152 \times 10$ & 103.6 & 14.2 & HSS $140 \times 140 \times 10$ & 94.6 & 12.8 \\
\hline 6 & HSS $178 \times 178 \times 13$ & 89.8 & 9.9 & HSS $152 \times 152 \times 13$ & 88.3 & 9.9 \\
\hline 5 & HSS $178 \times 178 \times 13$ & 89.8 & 9.9 & HSS $152 \times 152 \times 13$ & 88.3 & 9.9 \\
\hline 4 & HSS $178 \times 178 \times 13$ & 89.8 & 9.9 & HSS $152 \times 152 \times 13$ & 88.3 & 9.9 \\
\hline 3 & HSS $178 \times 178 \times 13$ & 89.8 & 9.9 & HSS $152 \times 152 \times 13$ & 88.3 & 9.9 \\
\hline 2 & HSS $203 \times 203 \times 13$ & 77.7 & 12.1 & HSS $178 \times 178 \times 13$ & 74.8 & 12.1 \\
\hline 1 & HSS $203 \times 203 \times 13$ & 77.7 & 12.1 & HSS $178 \times 178 \times 13$ & 74.8 & 12.1 \\
\hline
\end{tabular}




\section{Behavior of unbraced frames under compartment fires}

The behavior of unbraced frames exposed to compartment fires (Figure 2) was first investigated, and the collapse mechanism was presented. Figure 4 shows the typical collapse modes of the frames under interior and corner fires where the ground floor was removed to clearly illustrate the behavior of ground floor columns. The collapse was represented by the sequential buckling of columns from the fire compartment to the adjacent compartments, as well as lateral drift of columns. The lateral drift was more significant in the center fire due to catenary action in the heated beams and tensile membrane action in the heated slab. The variation of axial displacements of the heated columns and adjacent columns under single-compartment fires is shown in Figure 5. The temperature of the heated column is also shown in the figure (marked in red). The heated columns first buckled at about $30 \mathrm{~min}$ for both center and corner fire when its temperature reached about $550{ }^{\circ} \mathrm{C}$. This was followed by the first-round buckling of the adjacent columns along the short span (C2, C5, D2, D5 for the center fire; A3 for the corner fire), and then the second-round buckling of the adjacent columns along the long span (B3, B4, E3, E4 for the center fire; C1 for the corner fire). The buckling of the heated columns is because of the increasing compressive forces in them due to restrained thermal expansion and degrading material strength at elevated temperatures. The adjacent columns failed because of the increasing compressive forces in them due to load redistribution and lateral drift (P- $\Delta$ effect) driven by the large deflection of the heated slab. The first-round buckling of the adjacent columns along the short span is due to the uneven load redistribution in the two in-plane directions where more loads are redistributed along the short span $[28,29]$.

The failure time of the heated column is defined as the time when its axial displacement returns back to its initial displacement before heating. After this point, there is a sudden increment in the axial displacement and reduction in the axial force. However, the run-away failure of the heated columns was slowed down by the tensile load bearing capacity of beams and slabs, until the first-round buckling of the adjacent columns. This process is represented by a plateau in the load-displacement curve as shown in Figure 5. The first plateau for the heated columns lasted about $60 \mathrm{mins}$ and $40 \mathrm{mins}$ for the center fire and corner fire, respectively. A shorter second plateau occurred for the heated columns under center fire due to the further load redistribution to the adjacent columns along the long span. The adjacent columns of the frame under the center fire also experienced a plateau of 40 mins. The frame under a corner fire collapsed quickly after the first-round buckling of adjacent columns. This indicates that a fire at corner is more dangerous than that at interior since more uniform load redistribution and tensile membrane action of slabs may take effect in the interior fire. This load redistribution process and slab resistance can be seen as a "buffering time" that delays the collapse of the whole frame. It was found that the frame collapsed quickly after the second-round buckling of the adjacent columns, and thus the collapse time of the frame can be defined as the time when this phenomenon occurs.

Therefore, the key to mitigate the collapse of a frame is to uniformly redistribute loads to adjacent columns, and to limit the lateral drift of adjacent columns. The former can be achieved by using horizontal bracing, while the latter by vertical bracing. This feasibility for single-compartment fire was first investigated in the following section.

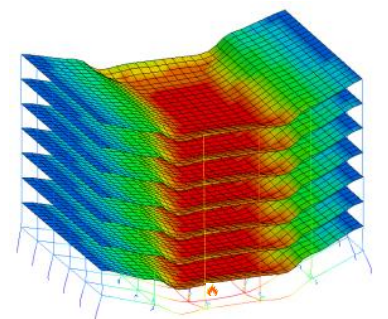

(a)

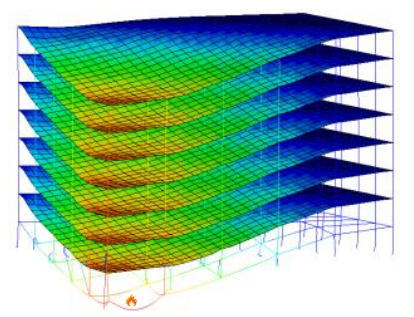

(b)

Fig. 4 Collapse modes of unbraced frames subject to: (a) fire at interior; (b) fire at corner

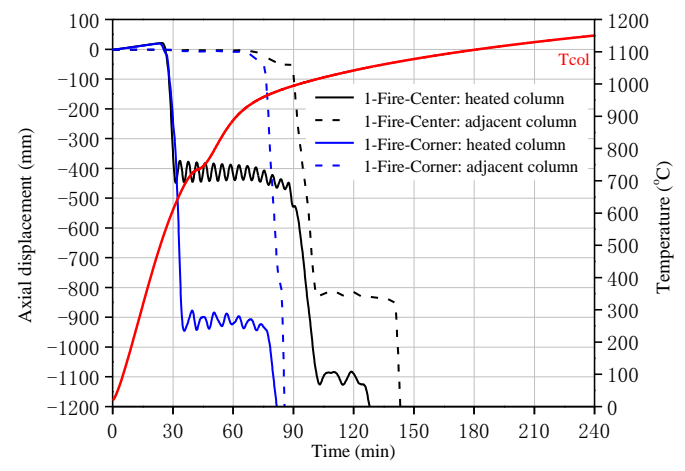

Fig. 5 Time histories of axial displacements of columns in the unbraced frames

\section{Behavior of braced frames under single-compartment fires}

\subsection{Horizontal bracing system}

Four layouts of horizontal bracing systems were considered: hat braces at perimeter (Hat-perimeter), hat braces on the whole floor (Hat-wholeFloor), belt braces at the middle height (Belt-middle), and combined hat and belt braces (Hat\&Belt). The layout of Hat-perimeter bracing and Belt-middle bracing is shown in Figures 6. The Hat-wholeFloor bracing is arranged between columns along the grid lines. The combined hat-belt bracing is a combination of Hat-perimeter and Belt-middle braces. For the belt braces, Smith and Coull [45] mentioned that the optimum location with one belt brace was in the middle height of the frame. So, one belt brace on the fourth storey was considered in this study. The influence of horizontal bracing systems on the collapse resistance of frames under the center and corner fire (Figure 2a) was investigated in this section.

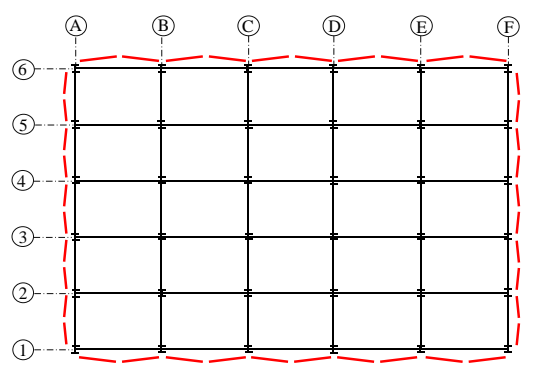

(a)

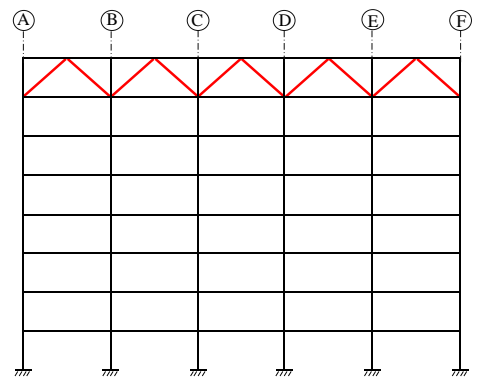

(b)

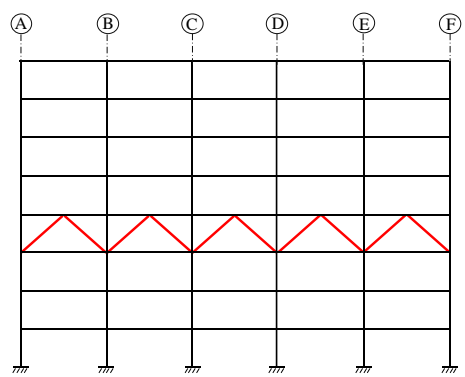

(c)

Fig. 6 Layout of horizontal bracing systems: (a) plan view; (b) elevation view of Hat-perimeter; (c) elevation view of Belt-middle 


\subsubsection{1-Fire-Center}

No collapse occurred for the frames with horizontal braces under a center fire. A comparison of axial displacements and axial forces of the heated and adjacent columns is shown in Figures 7 and 8, respectively. Due to the symmetry, the columns in the symmetric locations have the same responses. The Y-axis in Figure 8 represents the ratio of variation of axial forces in a column $\left(P-P_{0}\right)$ at elevated temperatures to its load-bearing capacity $P_{\mathrm{c}}$ at ambient temperature $\left(P_{\mathrm{c}}=7000 \mathrm{kN}\right.$ for edge columns and $P_{\mathrm{c}}=10000 \mathrm{kN}$ for internal columns). The parameters $P$ and $P_{0}$ represent the transient and initial axial force in the column, respectively. This ratio can be considered as the temperature-dependent load ratio. For the column exposed to fire, a positive value denotes the increasing axial compression in it due to the restrained thermal expansion. For an adjacent column at ambient temperatures, a positive value represents the increment in its axial force due to the load redistribution.

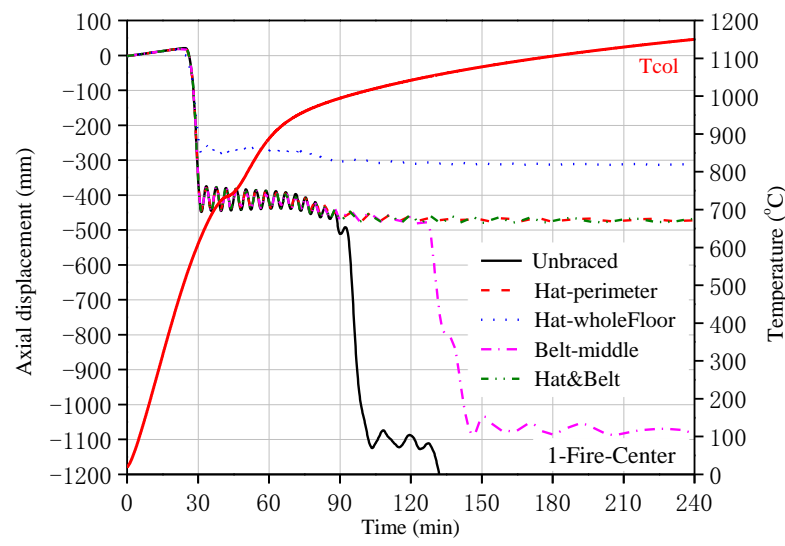

(a)

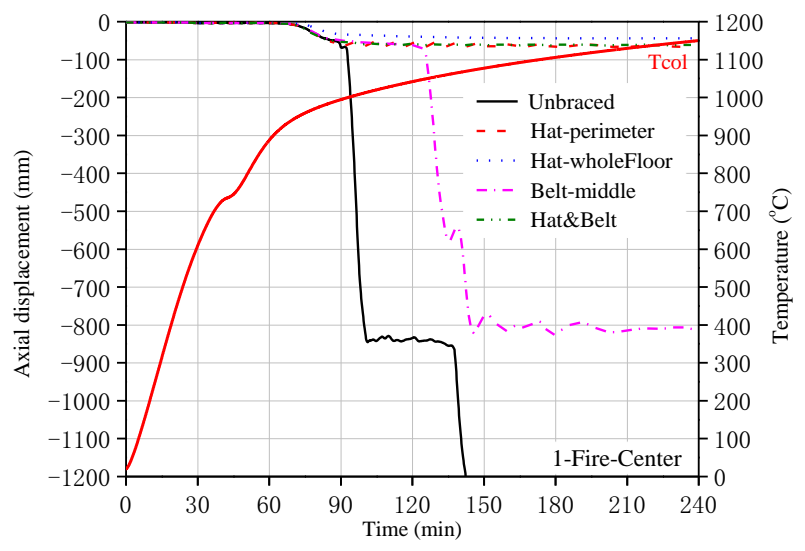

(b)

Fig. 7 Time histories of axial displacements of columns for 1-Fire-Center: (a) heated columns C3, C4, D3, D4; (b) adjacent columns C2, C5, D2, D5

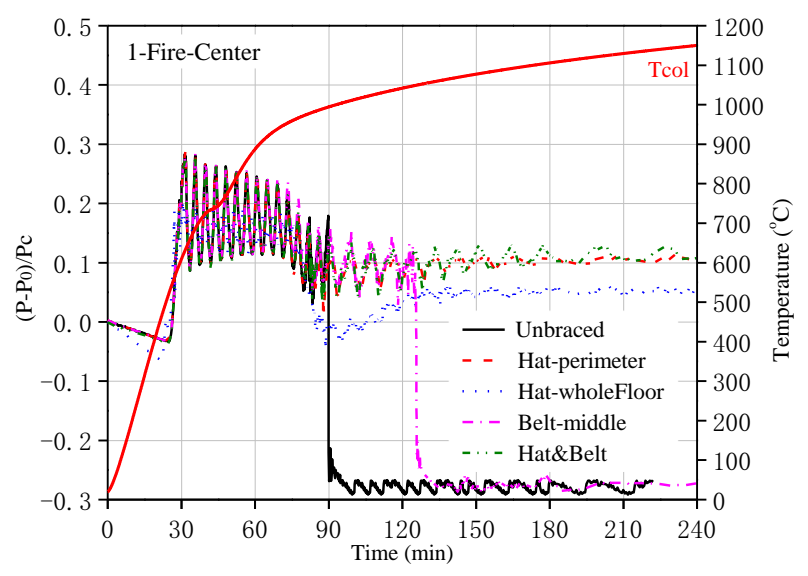

(a)

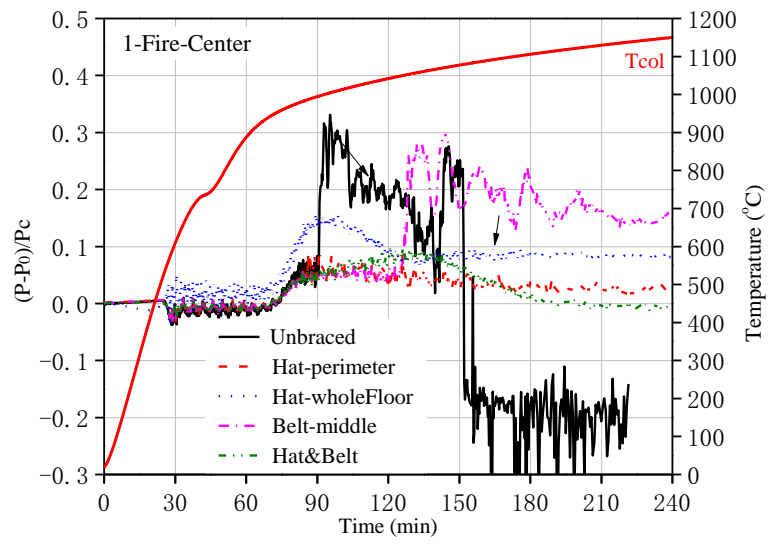

(b)

Fig. 8 Time histories of axial forces in columns for 1-Fire-Center: (a) adjacent columns C2, C5, D2, D5; (b) edge columns C1, C6, D1, D6

Figure 7a shows that the presence of horizontal braces had negligible effect on the buckling of the heated columns at about $30 \mathrm{~min}$, although the whole-floor hat braces produced larger axial forces in the heated columns compared to others. The variation of axial forces in the columns adjacent to the heated columns $(\mathrm{C} 2$, C5, D2, D5) and those at perimeter (C1, C6, D1, D6) was presented in Figure 8 since more loads were transferred to the columns along the short span. The loads initially carried by the heated columns were transferred to the adjacent columns (C2, C5, D2, D5), leading to an increment of 0.2 in load ratio for the Hat-wholeFloor braces, and 0.28 for others.

The load redistribution process took a period of about $60 \mathrm{mins}$ and $90 \mathrm{mins}$ for the unbraced frame and belt-braced frame, respectively. In contrast, the frames with hat braces and combined hat-belt braces withstood the fire since no adjacent columns failed (Figure 7b). The adjacent columns (C2, C5, D2, D5) in the belt-braced frame buckled. This may be because of the relatively larger dynamic effect on the ground floor columns caused by the failure of the heated columns, compared to the presence of horizontal braces on the top floor. This is shown in Figure 8a where the belt-braced frame had a larger increased load ratio than the hat-braced frame. In this case, the collapse was confined in a relatively small region of the frame rather than a disproportionately large part of it, and thus it was assumed that the frame with belt bracing did not disproportionately collapse. The loads were further redistributed to the columns along the edge through braces, leading to an increased load ratio of $0.3,0.15$ and 0.05 for the belt braces, whole-floor hat braces and perimeter hat braces, respectively (Figure 8b). It was found that the Hat-wholeFloor bracing had the best collapse-resisting effect since it led to the smallest axial displacement of the heated and adjacent columns (with a difference of more than $100 \mathrm{~mm}$ ). The presence of braces around the perimeter is sufficient to prevent collapse of the frame.

There was no buckling of braces, except those in the frame with Hat-wholeFloor. The braces in compression adjacent to the fire compartment buckled due to the large deflection of slabs.

\subsubsection{1-Fire-Corner}

Similarly, all the frames withstood the corner fire without run-away failure of adjacent columns, as shown in Figure 9b. The presence of hat braces (perimeter or whole floor) and belt braces held the failure of the heated columns at a large axial displacement of more than $700 \mathrm{~mm}$ (Figure 9a), compared to $170 \mathrm{~mm}$ for the combined hat-belt bracing. This large axial displacement is due to the buckling of braces above the fire compartment for these frames with single-type bracing systems. No buckling of braces occurred in the frame with combined hat-belt bracing where the deflection of the heated slab was greatly restrained. The presence of belt braces had a significant effect on the axial displacement of adjacent columns (Figure 9b). This indicates that the belt bracing had a better collapse resistance for the corner fire than a center fire. The perimeter and whole-floor hat braces had a similar effect on the buckling of adjacent columns, indicating that the interior presence of braces had little effect on the collapse resistance of the frame under a corner fire. The variation of axial forces in the heated columns was similar to that in the center fire. Figure 10 shows the variation of axial forces in the adjacent columns. The combined hat-belt bracing resulted in a smaller dynamic effect of load redistribution in the adjacent columns with an increased load ratio of 0.35, compared to $0.6,0.53,0.49,0.4$ for the unbraced frame, Belt-middle bracing, Hat-perimeter bracing, and Hat-wholeFloor bracing.

The belt braces placed in the middle height storey experience larger compressive forces than the hat braces, and thus become the weakness of horizontal bracing system. It was found that the frame with belt bracing alone 
would collapse under a corner fire if a smaller cross section of belt braces was taken (i.e. the same as the hat braces). The collapse was due to the sequential buckling of the belt braces in compression. While the frame with belt braces in a smaller section withstood the center fire.

The above results show that hat bracing and belt bracing had a good performance for the center fire and corner fire, respectively. A combined hat and belt bracing is recommended in view of the uncertainty of fire locations. Special attention should be paid to the strength of the belt braces to prevent the global collapse of frames.

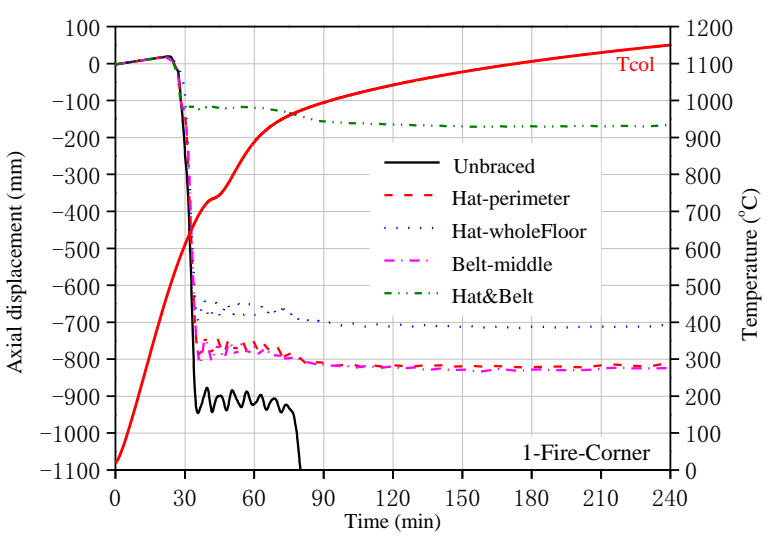

(a)

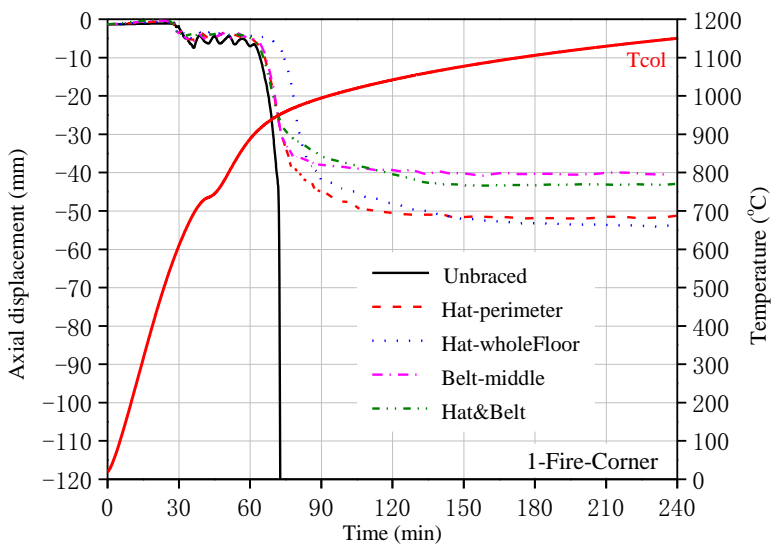

(b)

Fig. 9 Time histories of axial displacements of columns for 1-Fire-Corner: (a) heated column B2; (b) adjacent column A3

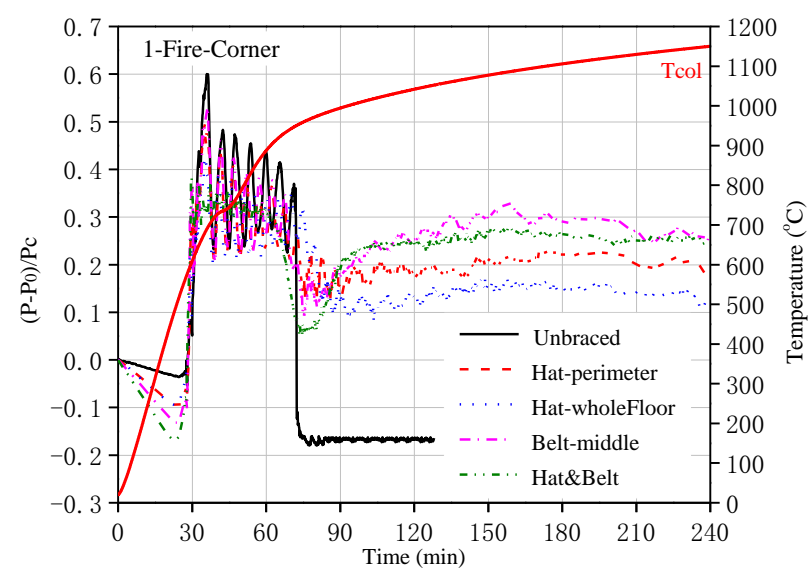

(a)

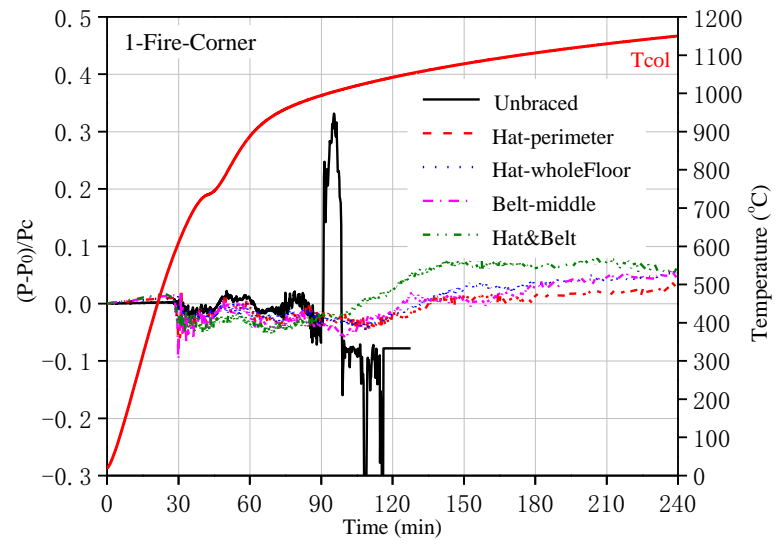

(b)

Fig. 10 Time histories of axial forces of columns for 1-Fire-Corner: (a) adjacent column A3; (b) edge column A6

\subsection{Vertical bracing system}

Three locations of vertical bracing systems were considered: one braced bay at midspan (Vertical-midspan), two braced bays at interior (Vertical-interior), two braced bays at ends (Vertical-end). The layout of these vertical braces is illustrated in Figure 11.

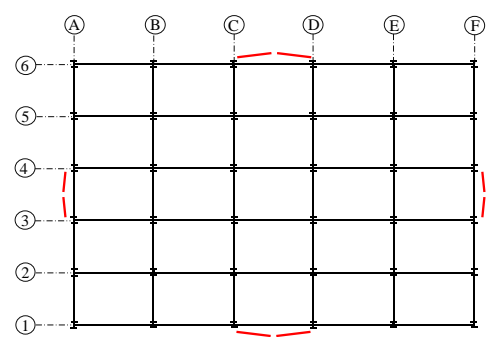

(a)

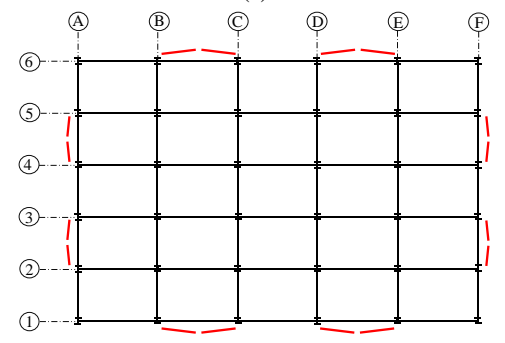

(b)

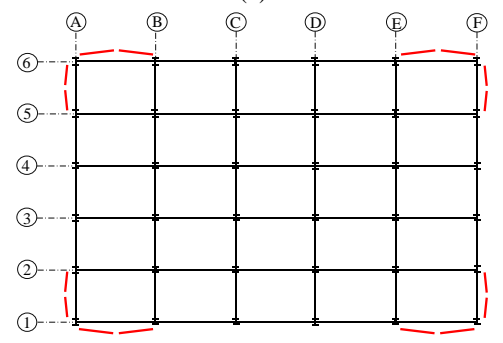

(c)

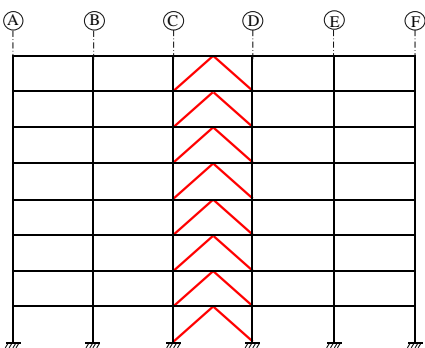

(d) 


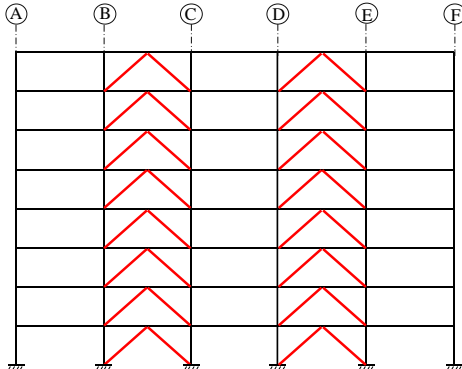

(e)

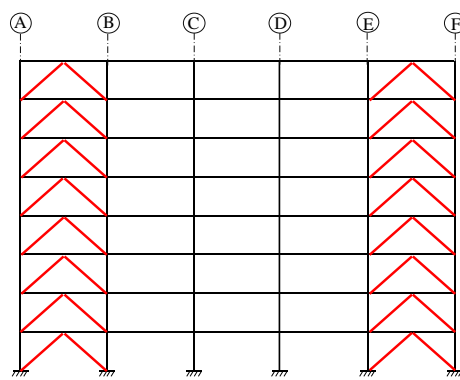

(f)

Fig. 11 Layout of vertical bracing systems: (a) plan view of Vertical-midspan; (b) plan view of Vertical-interior; (c) plan view of Vertical-end; (d) elevation view of Vertical-midspan; (e) elevation view of Vertical-interior; (f) elevation view of Vertical-end

\subsubsection{1-Fire-Center}

The frame with Vertical-end bracing collapsed, while the other frames withstood. Figure 12 shows the collapse mode at the end of the analysis where all the adjacent columns along the short span buckled but no global collapse occurred. In this case we assume that the frame with Vertical-end bracing collapses since a disproportionately large part of the frame collapses. Compared to the withstanding of adjacent columns in the frame with interior braces, the failure of adjacent columns in the frame with end braces was because of their large lateral displacements since the presence of braces at ends had limited effect on the lateral resistance of columns at interior. The large lateral displacement caused large P- $\Delta$ effect in the columns, resulting in their buckling. The collapse of the frame with end braces alone indicates the importance to apply vertical braces at the interior bays. The variation of axial displacements and axial forces of columns is shown in Figures 13 and 14, respectively. The frame with end braces collapsed at about 200 min (Figure 13b), which was a delay of 60 mins from the first-round buckling of the adjacent columns (C2, C5, D2, D5). The collapse time of the frame is defined herein as the second-round failure of adjacent columns (B3, B4, E3, E4 in this case), after which the frame may collapse quickly. The frames with midspan and interior bracing showed similar behavior.

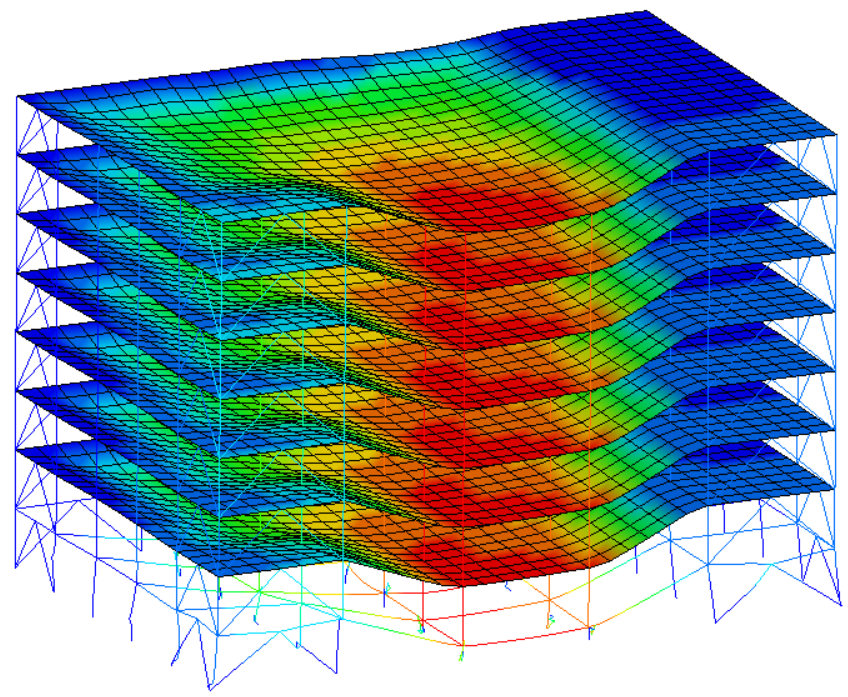

Fig. 12 Collapse of the frame with Vertical-end bracing under 1-Fire-Center (at $240 \mathrm{~min}$ )

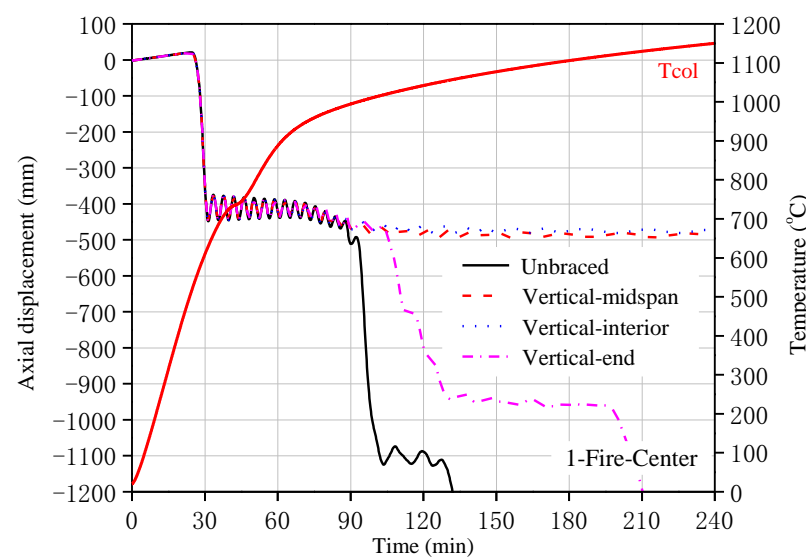

(a)

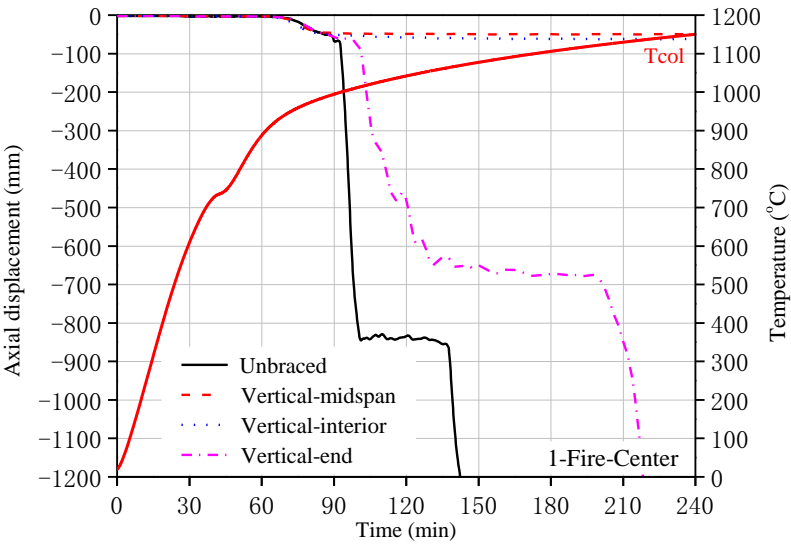

(b)

Fig. 13 Time histories of axial displacements of columns for 1-Fire-Center: (a) heated columns C3, C4, D3, D4; (b) adjacent columns C2, C5, D2, D5

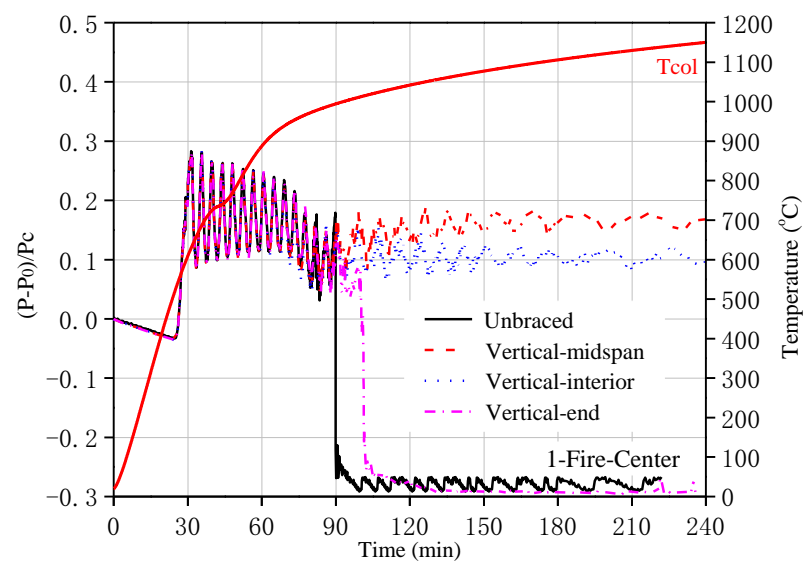

Fig. 14 Time histories of axial forces in the adjacent columns C2, C5, D2, D5 for 1-Fire-Center

\subsubsection{1-Fire-Corner}

No frame with vertical bracing collapsed under corner fire. The Vertical-interior bracing had the best collapse resistance since it led to the smallest axial displacement $(170 \mathrm{~mm})$ of the heated columns, compared to more than 800 $\mathrm{mm}$ for the other two layouts, as shown in Figure 15. This is because the interior bracing was just placed adjacent to the fire compartment, and thus provided strong vertical support to the storey above the fire compartment. The variation of axial forces in the adjacent column A3 is shown in Figure 16. For the interior-braced frame, the column A3 located at the un-exposed side of the bracing system which experienced large uplift effect of the bracing system at the early stage of heating, leading to reducing axial forces (Figure 16)

The results in this section show that the frame with two braced bays at interior had a good performance under both center and corner fire. The presence of vertical braces at interior is important to enhance the collapse resistance. In practice, the vertical braces are always used in a combination of horizontal braces, and the behavior of frames with combined horizontal-vertical bracing systems was studied in the next section. 


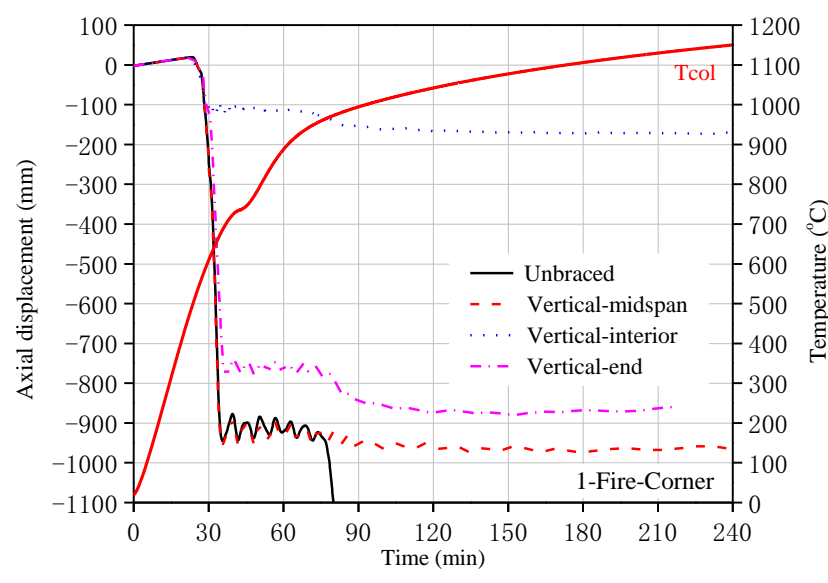

(a)

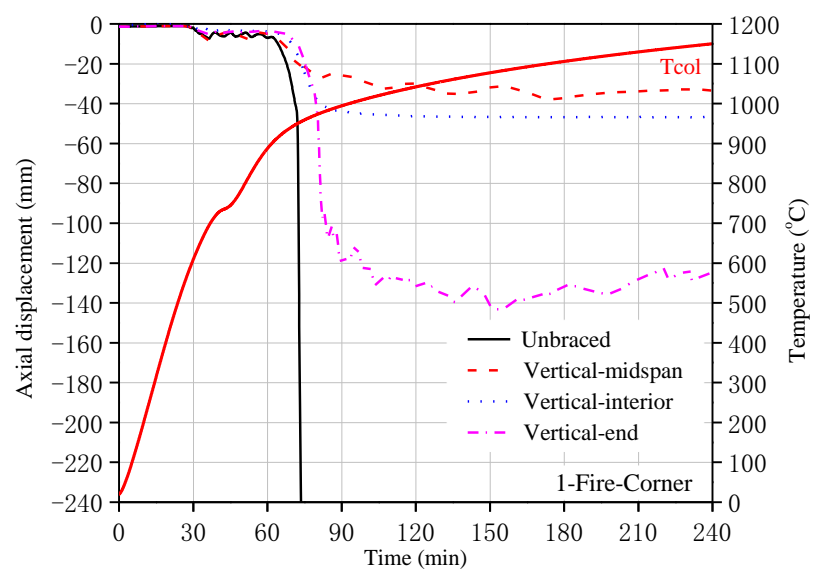

(b)

Fig. 15 Time histories of axial displacements of columns for 1-Fire-Corner: (a) heated columns B2; (b) adjacent columns A3

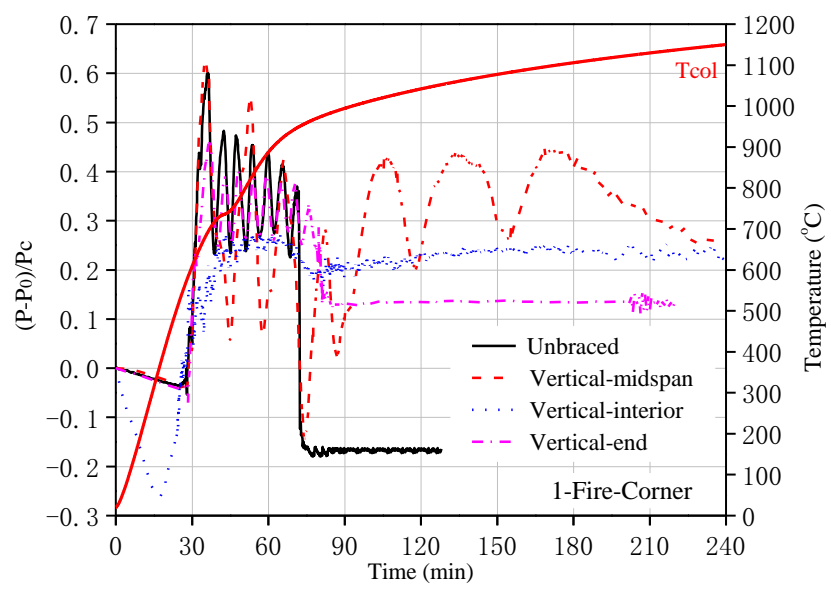

Fig. 16 Time histories of axial forces of the adjacent column A3 for 1-Fire-Corner

\subsection{Combined horizontal and vertical bracing system}

A combination of hat braces at perimeter, belt braces in the middle height, and vertical braces at interior or ends was used in this section. Four layouts of combined bracing systems were modelled: Hat\&Vertical-interior, Hat\&Belt\&Vertical-interior, Hat\&Vertical-end, Hat\&Belt\&Vertical-end, as shown in Figure 17. The frame with Hat\&Vertical-end bracing under the center fire collapsed, while the other frames withstood both the center and corner fire. Compared to the buckling of braces in the frame with Hat-perimeter bracing under a corner fire, the presence of vertical braces at interior prevented the buckling of hat braces. However, there was still buckling of hat braces in the frame with vertical braces at ends, which was prevented by adding belt braces.

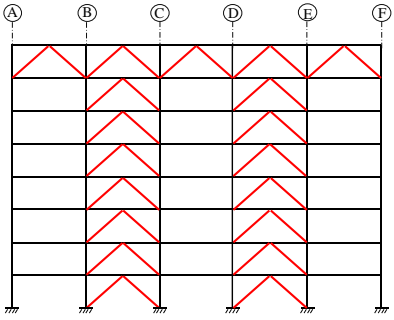

(a)

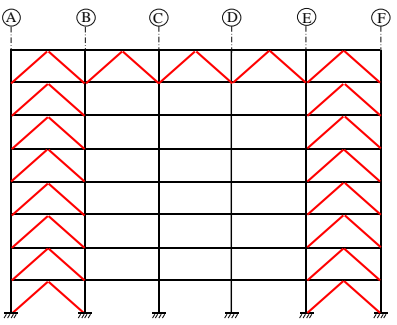

(c)

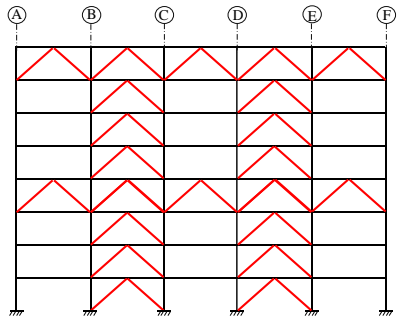

(b)

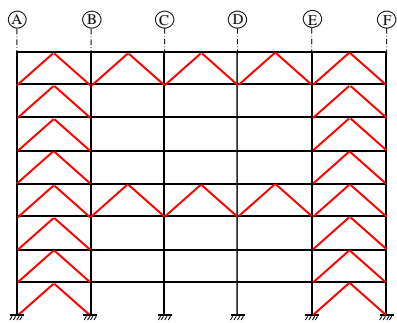

(d)
Fig. 17 Elevation view of combined horizontal and vertical bracing systems: (a) Hat\&Vertical-interior; (a) Hat\&Belt\&Vertical-interior; (c) Hat\&Vertical-end; (d) Hat\&Belt\&Vertical-end

A comparison of axial displacements of adjacent columns is shown in Figure 18. It shows that the presence of vertical braces at interior had a much better effect on prevention of fire-induced collapse of the frame. The application of horizontal braces in the vertically braced frame helps to enhance the collapse resistance by reducing the axial displacements of columns. For the center fire, the combined horizontal and vertical bracing had negligible effect on the axial forces of adjacent columns since they showed a similar dynamic effect to those for individual bracing systems as shown in Figure 8 and Figure 14. The effect of combined horizontal-vertical bracing on the dynamic effect was more significant for the corner fire as shown in Figure 19, where the vertical braces at interior showed a better performance. This enhancement was more significant for the corner fire due to the greater effect of the horizontal bracing in the corner fire.

Therefore, from the perspective of efficiency and cost effectiveness, the optimal layout of bracing systems to resist single-compartment fires is the combination of hat braces at perimeters and vertical braces at interior. The frame with this combined bracing showed good collapse resistance and reduced dynamic effect for both center and corner fires.

\section{Behavior of braced frames under multi-compartment fires}

The results in the previous section verify that it is feasible to use a single type of bracing systems (horizontal or vertical) to prevent collapse of frames subject to single-compartment fires. A combination of horizontal and vertical braces can improve the collapse resistance by reducing the axial displacement of columns. This section is to check the collapse behavior of braced frames under multi-compartment fires (Figure 2b). The frames withstood the single-compartment fires were considered herein. It was found that all the frames with a single type of bracing systems (horizontal or vertical) collapsed under multi-compartment fires. The frames collapsed immediately after the first-round buckling of adjacent columns, with similar collapse modes as shown in Figure 4.

The frame with the optimal combined bracing system (hat-perimeter and vertical-interior) for single-compartment fires withstood the 3-Fire-Short fire although it suffered from the buckling of adjacent columns at $78 \mathrm{~min}$. However, it collapsed at $67 \mathrm{~min}$ and $33 \mathrm{~min}$ for 3-Fire-Long and 4-Fire-Corner, respectively. The application of belt braces in this optimal bracing layout cannot prevent the collapse. Compared to single-compartment fires, the first-round buckling of adjacent columns advanced due to the severity of multi-compartment fires. The time interval between the heated and adjacent columns decreased to 40 mins for the 3-Fire-Long fire, compared to at least $60 \mathrm{mins}$ for 1-Fire-Center. The 4-Fire-Corner is the severest fire scenario since the frame collapsed immediately after the buckling of the heated columns. To strengthen the bracing system, whole-floor hat braces were used instead of perimeter hat braces in the combined Hat\&Belt\&Vertical-interior bracing system. It was found that the strengthened frame withstood the 3-Fire-Long fire but still collapsed for 4-Fire-Corner. However, a further enhancement in the bracing systems (e.g. adding vertical braces at ends) cannot prevent the collapse of the frame under 4-Fire-Corner because the application of bracing systems is insufficient to prevent the buckling of adjacent columns which experienced large compressive axial forces due to the load redistribution.

As an alternative, fire protections were applied on the perimeter columns of the frame with Hat-wholeFloor\&Belt\&Vertical bracing. The temperature time 
history of the protected columns is shown in Figure 3. The protected frame withstood the 4-Fire-Corner fire, as shown in Figure 20. The protected columns in the fire compartment withstood for a period of 130 mins until its temperature reached about $400{ }^{\circ} \mathrm{C}$. Figure 21 shows the variation of axial forces in adjacent columns of the braced frames under multi-compartment fires. The presence of whole-floor hat braces significantly reduced the dynamic effect, compared to perimeter hat braces.

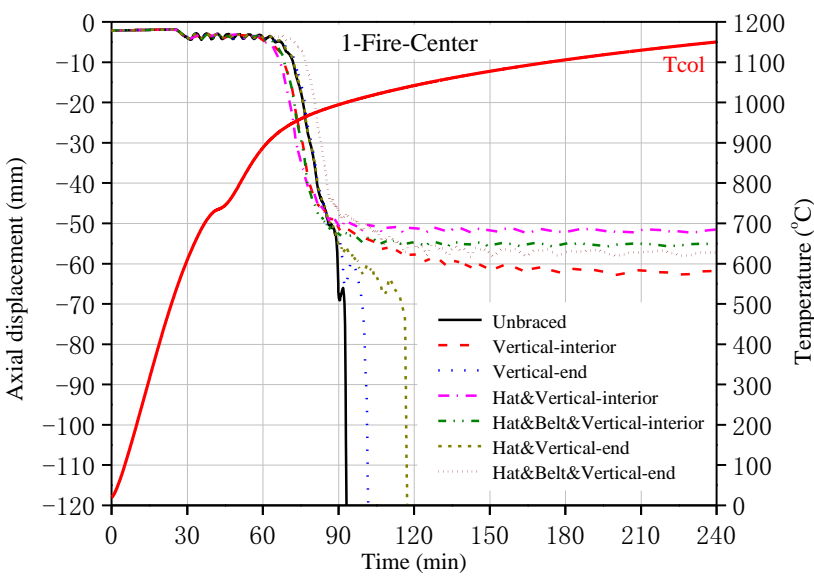

(a)

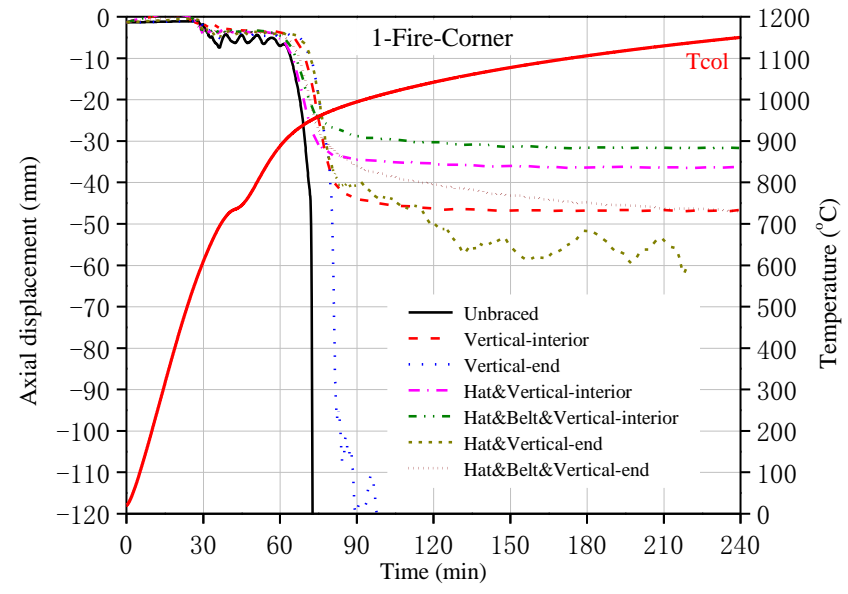

(b)

Fig. 18 Time histories of axial displacements of adjacent columns for: (a) 1-Fire-Center (C2, C5, D2, D5); (b) 1-Fire-Corner (A3)

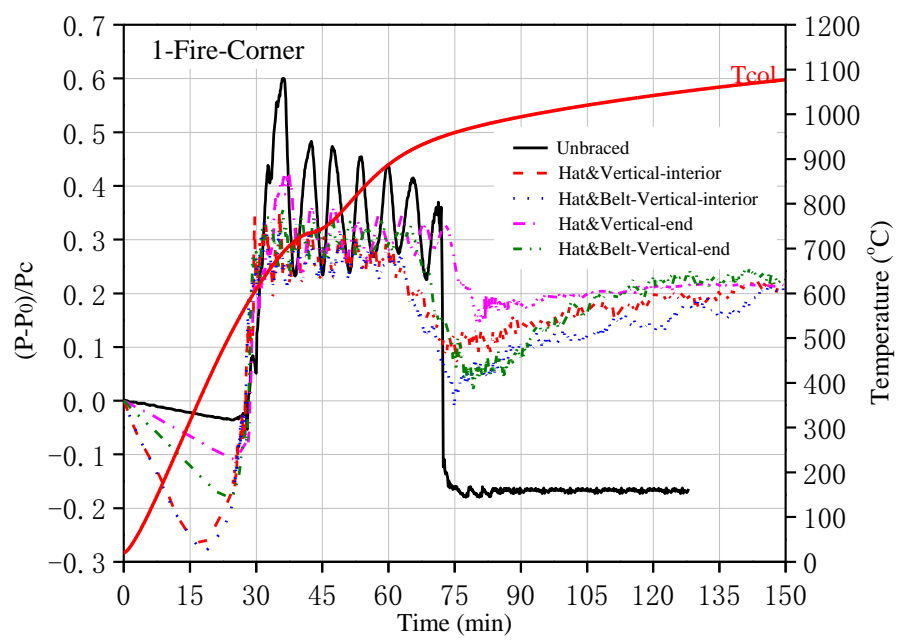

Fig. 19 Time histories of axial forces of the adjacent column A3 for combined horizontal-vertical bracing under 1-Fire-Corner

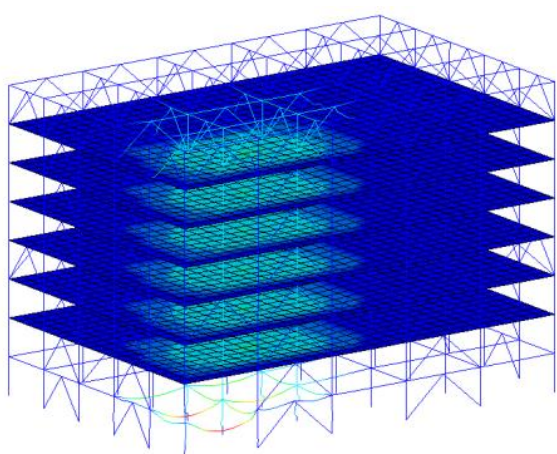

(a)

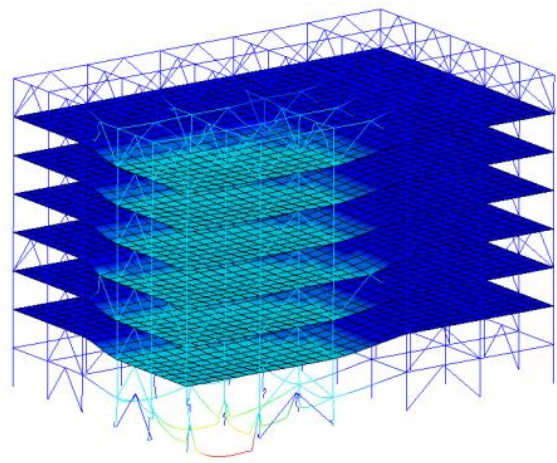

(b)

Fig. 20 Behavior of braced frame with Hat-wholeFloor\&belt \&Vertical\&Protection bracing under 4-Fire-Corner: (a) first buckling of the protected columns at $130 \mathrm{~min}$; (b) at $240 \mathrm{~min}$

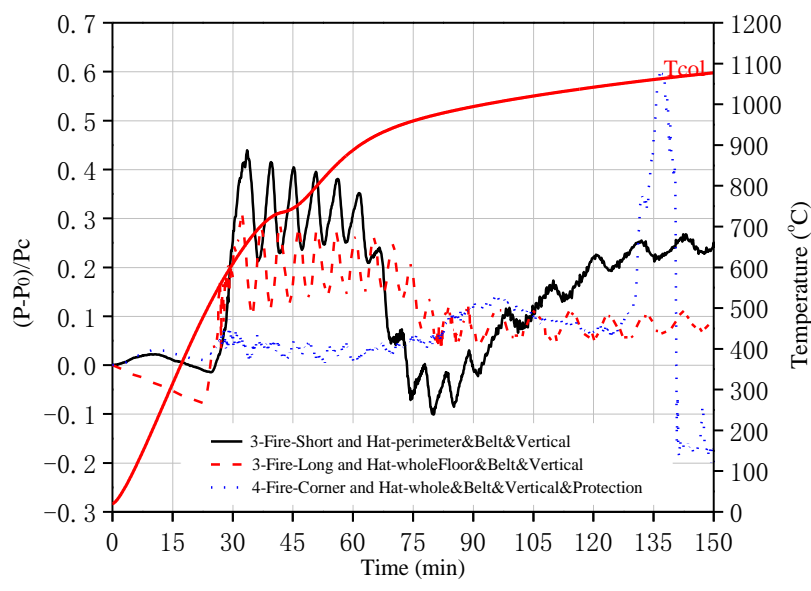

Fig. 21 Time histories of axial forces of the adjacent columns for combined horizontal-vertical bracing under multi-compartment fires

\section{Discussion}

\subsection{Selection of bracing systems}

A single type of bracing systems (horizontal or vertical) is sufficient to resist the collapse of frames under a single-compartment fire. This means that if fire doors (or fire walls) are used for the compartmentation of a building, the amount of bracing systems can be reduced to the extent that only applying hat braces around the perimeter or vertical braces at the midspan bay. However, due to the uncertainty in the number and location of fire compartments, it is safer to use a combination of horizontal and vertical braces (i.e. combined hat-belt-vertical bracing). This combined bracing system can be used to prevent disproportionate collapse of the frame subject to interior fires, but may fail for corner fire. This means that efforts should be taken to prevent the multi-compartment fires at corner of the frame (e.g. enhancing the amount of fire doors or sprinkler systems). In this case no fire protection is needed. Otherwise, it is recommended to protect the perimeter columns on the ground floor to enhance the collapse resistance of the frame against potential multi-compartment fires at corner. This indicates that 
effective fire partition, especially at corner of a building, can reduce the amount of bracing and fire protection.

\subsection{Effect of slabs}

The presence of concrete slabs has beneficial influence on the collapse resistance of frames exposed to fire. The heated slab did not collapse for single-compartment fire at center, but collapsed for multi-compartment fires at interior. As temperature increases, the load bearing mechanism of slabs changes from bending to tensile membrane action. The tensile membrane action in the heated slab is provided by the tensile forces in the reinforcement which is resisted by tensile forces in the reinforcement of adjacent slabs at ambient temperatures. If the buckling of columns is confined in a relatively small region (e.g. a braced frame under single-compartment fire at interior), the tensile forces in the reinforcement of the heated slab are resisted by a tensile ring around its perimeter provided by the reinforcement of adjacent slabs at ambient temperatures, as shown in Figure 22a. The points in while represent the location of columns. For a large area of buckling of columns, the tensile forces in the reinforcement of the heated slab are also maintained by four tensile yielding lines extended to the edge of the frame, as shown in Figure 22b and Figure 22c. The load bearing mechanism of slabs is important for the collapse resistance of frames since a smaller deflection of the slab will lead to a smaller lateral displacement of the columns, and thus a smaller P- $\Delta$ effect. This indicates the necessity to enhance the fire resistance of columns to provide sufficient vertical support for slabs. This can be achieved by increasing its fire protection level or placing vertical bracing systems at the interior of the frame. It is also suggested to increase the cross-section of columns along the edges of the frame to provide strong resistance for the development of tensile forces in the reinforcement of slabs.

Compared to the survival of the heated slab in the interior fire, the heated slab exposed to the corner fire collapsed. This is because of the loss of vertical support due to the buckling of the heated columns. The falling down of slabs is dangerous since it will impose large dynamic effect on the storey below, and thus cause storey-by-storey collapse of the frame. This again indicates that a corner fire is more dangerous than an interior fire.
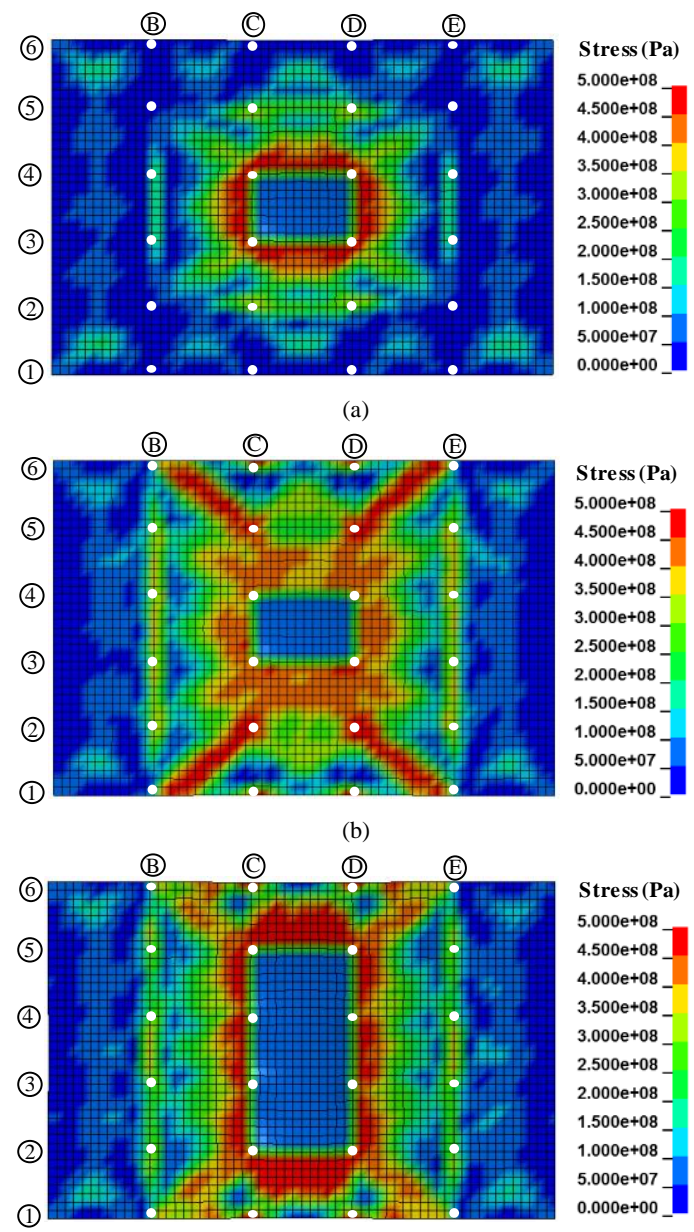

(c)

Fig. 22 Distribution of maximum in-plane stress in the reinforcement of the ground-floor slabs: (a) frame with Hat-perimeter bracing under 1-Fire-Center (at $180 \mathrm{~min}$ ); (b) frame with Belt-middle bracing under 1-Fire-Center (at $180 \mathrm{~min}$ ); (c) frame with Hat-perimeter\&Belt\&Vertical bracing under 3-Fire-Short (at $180 \mathrm{~min}$ )

\section{Conclusions}

This paper investigated the effect of bracing systems on the collapse resistance of 3D steel frames subjected to single and multi-compartment fires on the ground floor. The horizontal and vertical bracing systems as well as their combination were considered. The following conclusions can be drawn:

(1) It is feasible to use bracing systems to enhance the collapse resistance of steel framed buildings. The presence of braces was beneficial for uniformly redistributing loads, limiting lateral drift of columns, and restraining deflection of slabs. The collapse of braced frames can be delayed by 60 mins compared to unbraced frames.

(2) The collapse of frames under a single-compartment fire can be prevented by using either horizontal or vertical braces. A combination of hat braces at perimeter and vertical braces at interior is recommended since it showed a better performance for both interior and corner fires. It was found that the presence of vertical braces at interior bays of a frame was essential to prevent its collapse.

(3) For a severer fire scenario of multi-compartment fire, it is necessary to use a combined horizontal and vertical bracing system. The combined hat-belt-vertical bracing can prevent the collapse of the frame under multi-compartment fires at interior of the frame. It is better to place hat braces on the whole floor to provide a more uniform load redistribution and strong restraint on the deflection of slabs. For a multi-compartment fire at corner, it is necessary to apply fire protection on the perimeter columns (e.g. 3-h fire rating) to prevent the collapse of the frame.

(4) A corner fire may cause the buckling of horizontal braces in compression. A combination of hat and belt braces or combination of vertical braces at interior can prevent the buckling of braces.

(5) The slabs have beneficial influence on the collapse resistance of frames exposed to fire. At high temperatures, the heated slabs resist loads by tensile membrane action which is resisted by a tensile ring around the perimeter of the heated slab provided by the adjacent slabs at ambient temperature. They can also be resisted by tensile yield lines extended to the edge of the frame when a large number of columns failed.

(6) For fires at corner is more dangerous than those at interior, it is suggested to conduct fire partition at corner of buildings to ensure that the fire is confined in one compartment without spread to adjacent compartments. This fire partition is beneficial from the economic perspective since it can reduce the amount of bracing systems and fire protection demands.

\section{Acknowledgements}

The work presented in this paper was supported by the National Natural Science Foundation of China with grant 51538002 and 51408418, and Research project of State Key Laboratory for Disaster Reduction in Civil Engineering with grant SLDRCE14-A-05.

\section{References}

[1] Kirby B.R., British Steel Technical European Fire Test Program Design, Construction and Results. Fire, Static and Dynamic Tests of Building Structures. London, 1997.

[2] Hayes J.R., Woodson S.C., Pekelnicky R.G. et al., "Can strengthening for earthquake improve blast and progressive collapse resistance?” Journal of Structural Engineering, 131(8), 1157-1177, 2005

[3] Khandelwal K. and EI-Tawil S., "Collapse behavior of steel special moment resisting frame connections." Journal of Structural Engineering, 133(5), 646-655, 2007.

[4] Menchel K., Massart T., Rammer Y., and Bouillard P., "Comparison and study of different progressive collapse simulation techniques for RC structures." Journal of Structural Engineering, 135(6), 685-697, 2009

[5] Li G.Q., Zhang Y., Yang T.C., Jiang J., et al., "Effect of blast-induced column failure pattern on collapse behavior of steel frames" Advanced Steel Construction, 14(3), 376-390, 2018.

[6] Zhang J., Xu Y.X., Yang X.J. et al., "Fire resistance study of restrained steel columns with initial lateral displacement." Advanced Steel Construction, 14(1), 22-36, 2018.

[7] Minimum Design Loads for Buildings and Other Structures, American Society of Civil Engineers (ASCE), ASCE 7, Reston, Virginia, 2005.

[8] Design of Buildings to Resist Progressive Collapse, Department of Defense (DoD), UFC 4-023-03, Washington, DC, 2010.

[9] Progressive Collapse Analysis and Design Guidelines for New Federal Office Buildings and Major Modernization Projects, General Services Administration (GSA), Washington, DC, 2003.

[10] Richard Liew J.Y. and Chen H., "Explosion and fire analysis of steel frames using fiber element approach." Journal of Structural Engineering, 130(7), 991-1000, 2004.

[11] Porcari G.L.F, Zalok E. and Mekky W., "Fire induced progressive collapse of steel building structures: A review of the mechanisms." Engineering Structures, 82, 261-267, 2015.

[12] Usmani A.S., Chung Y.C. and Torero J.L., "How did the WTC towers collapse: a new theory." Fire Safety Journal, 38, 501-533, 2003.

[13] Usmani A.S., "Stability of the World Trade Center twin towers structural frame in multiple floor fires." Journal of Engineering Mechanics, 131(6), 654-657, 2005.

[14] Flint G., Usmani A.S., Lamont S., Lane B. and Torero J., "Structural response of tall buildings to multiple floor fires." Journal of Structural Engineering, 133(12), 1719-1732, 
2007

[15] Lange D., Roben C. and Usmani A.S., "Tall Building Collapse Mechanisms Initiated by Fire: Mechanisms and Design Methodology.” Engineering Structures, 36, 90-103, 2012.

[16] Quiel S.E. and Garlock M.E.M., "Modeling high-rise steel framed buildings under fire." Proceedings of Structures Congress, Vancouver, British Columbia, Canada, 2008.

[17] Sun R.R., Huang Z. H. and Burgess I., "Progressive Collapse Analysis of Steel Structures under Fire Conditions." Engineering Structures, 34, 400-413, 2012

[18] Jiang J., Li G.Q. and Usmani A.S., "Progressive collapse mechanisms of steel frames exposed to fire." Advances in Structural Engineering, 17(3), 381-398, 2014.

[19] Jiang J., Li G.Q. and Usmani A.S., "Influence of Fire Scenarios on Progressive Collapse Mechanisms of Steel Framed Structures." Steel Construction-Design and Research, 7, 169-172, 2014.

[20] Jiang B.H., Li G.Q. and Usmani A.S., "Progressive collapse mechanisms investigation of planar steel moment frames under localized fire." Journal of Constructional Steel Research, $115,160-168,2015$

[21] Ma K.Y. and Richard Liew J.Y., "Nonlinear plastic hinge analysis of three-dimensional steel frames in fire." Journal of Structural Engineering, 130(7), 981-990, 2004.

[22] Wang W., Wang J.J., Sun X. and Bao Y.H., "Slab effect of composite subassemblies under a column removal scenario.” Journal of Constructional Steel Research, 129, 141-155, 2017.

[23] Pham X.D. and Tan K.H., "Membrane actions of RC slabs in mitigating progressive collapse of building structures." Engineering Structures, 55, 107-115, 2013.

[24] Fan S.G., Sun W.J., Wei H.Z and Liu M.J., "Research on the membrane action of profiled steel sheet-concrete composite floors in fire." Advanced Steel Construction, 11(4), 469-491, 2015.

[25] Pyl L., Schueremans L., Dierckx W. and Georgieva I., "Fire safety analysis of a 3D frame structure based on a full-scale fire test." Thin-Walled Structures, 61, 204-212, 2012.

[26] Kilic S.A. and Selamet S., "Symmetric and asymmetric collapse mechanisms of a multi-story steel structures subjected to gravity and fire." Structures Congress, Pittsburgh, PA, 2545-2552, 2013

[27] Agarwal A. and Varma A.H., "Fire induced progressive collapse of steel building structures: The role of interior gravity columns." Engineering Structures, 58, 129-140, 2014.

[28] Jiang J. and Li G.Q., "Progressive collapse analysis of 3D steel frames with concrete slabs exposed to localized fire." Engineering Structures, 149, 21-34, 2017.

[29] Jiang J. and Li G.Q., "Disproportional Collapse of 3D Steel-framed Structures Exposed to Various Compartment Fires.” Journal of Constructional Steel Research, 138, 594-607, 2017.

[30] World Trade Center Building Performance Study, Federal Emergency Management Agency (FEMA), Report 403, Washington D.C., 2002.
[31] Talebi E., Tahir M.M., Zahmatkesh F. et al., "Fire resistance of a damaged building employing buckling restrained braced system." Advanced Steel Construction, 14(1), 1-21, 2018.

[32] Kim J., Lee Y. and Choi H., "Progressive collapse resisting capacity of braced frames." The Structural Design of Tall and Special Buildings, 20, 257-270, 2011.

[33] Asgarian B. and Rezvani F. H., "Progressive collapse analysis of concentrically braced frames through EPCA algorithm.” Journal of Constructional Steel Research, 70, 127-136, 2012.

[34] Chen J.L., Peng W.B., Ma R.L. and He M.J., "Strengthening of horizontal bracing on progressive collapse resistance of multistory steel moment frame." Journal of Performance of Constructed Facilities, 26(5), 720-724, 2012.

[35] Tsai M.H., "A performance-based design approach for retrofitting regular building frames with steel braces against sudden column loss." Journal of Constructional Steel Research, 77 , $1-11,2012$.

[36] Main J.A. and Liu J., "Robustness of prototype steel frame buildings against column loss assessment and comparisons." Structures Congress, Pittsburgh, PA, 2013.

[37] Sun R.R., Huang Z.H. and Burgess I., "The collapse behaviour of braced steel frame exposed to fire." Journal of Constructional Steel Research, 72, 130-142, 2012.

[38] Jiang J., Li G.Q. and Usmani A.S., "Effect of bracing systems on the fire-induced progressive collapse of steel structures." Fire Technology, 51, 1249-1273, 2015.

[39] Design of steel structures, Part 1.2: General Rules-Structural Fire Design, European Committee for Standardization (CEN), EN 1993-1-2, Brussels, 2005

[40] Li G.Q., Wang W.Y. and Chen S.W., "A simple approach for modeling fire-resistance of steel columns with locally damaged fire protection." Engineering Structures, 31, 617-622, 2009.

[41] Design of composite steel and concrete structures, Part 1.2: General Rules-Structural Fire Design, European Committee for Standardization (CEN), EN 1994-1-2, Brussels, 2005.

[42] Design of Concrete Structures, Part 1.2: General Rules - Structural Fire Design, European Committee for Standardization (CEN), EN 1992-1-2, Brussels, 2004

[43] Seismic Provisions for Structural Steel Buildings, American Institute of Steel Construction (AISC), AISC 341, Chicago, 2005

[44] Ghosh S.K., Assessing Ability of Seismic Structural Systems to Withstand Progressive Collapse: Design of Steel Braced Frame Buildings, Report Prepared by S.K. Ghosh \& Associates, Inc., Palatine, IL., 2006.

[45] Smith B.S. and Coull A. Tall Building Structures: Analysis and Design. Wiley Interscience Publication, USA, 1991. 